AperTO - Archivio Istituzionale Open Access dell'Università di Torino

\title{
Multi-Technique Characterization of Adhesives Used in Medieval Jewellery
}

\section{This is the author's manuscript}

Original Citation:

Availability:

This version is available http://hdl.handle.net/2318/1631667

since 2017-07-25T15:43:13Z

Published version:

DOI:10.1111/arcm.12297

Terms of use:

Open Access

Anyone can freely access the full text of works made available as "Open Access". Works made available under a Creative Commons license can be used according to the terms and conditions of said license. Use of all other works requires consent of the right holder (author or publisher) if not exempted from copyright protection by the applicable law. 


\title{
MULTI-TECHNIQUE CHARACTERIZATION OF ADHESIVES USED IN MEDIEVAL JEWELLERY*
}

\author{
M. ACETO,${ }^{1,2} \dagger$ E. AGOSTA, ${ }^{1}$ A. ARRAIS, ${ }^{1}$ E. CALÀ, ${ }^{1}$ E. MAZZUCCO,${ }^{1}$ S. LOMARTIRE,${ }^{2,3}$ \\ A. AGOSTINO ${ }^{4,5}$ and G. FENOGLIO ${ }^{4,5}$ \\ ${ }^{I}$ Dipartimento di Scienze e Innovazione Tecnologica (DISIT), Università degli Studi del Piemonte \\ Orientale, viale Teresa Michel 1115121 Alessandria, Italy \\ ${ }^{2}$ Centro Interdisciplinare per lo Studio e la Conservazione dei Beni Culturali (CenISCo), Università degli \\ Studi del Piemonte Orientale, Piazza Sant'Eusebio 513100 Vercelli, Italy \\ ${ }^{3}$ Dipartimento di Studi Umanistici (DISUM), Università degli Studi del Piemonte Orientale, via Galileo \\ Ferraris 11613100 Vercelli, Italy \\ ${ }^{4}$ Dipartimento di Chimica, Università degli Studi di Torino, via P. Giuria 710125 Torino, Italy \\ ${ }^{5}$ Centro Interdipartimentale per lo Sviluppo della Cristallografia Diffrattometrica (CRISDI), Università \\ degli Studi di Torino, via P. Giuria 710125 Torino, Italy
}

\begin{abstract}
In this work, a multi-technique analytical approach was used to characterize adhesive samples taken from medieval chef d'oeuvres jewellery, three manuscript bindings and a crucifix produced in northern Italy between the 8th and the 11th century AD, according to arthistorical evaluation and ${ }^{14} \mathrm{C}$ dating executed on adhesives. These materials being complex mixtures, mostly of organic/inorganic nature, various analytical techniques were utilized to thoroughly elucidate their composition. A preliminary survey with portable X-ray fluorescence spectrometry $(X R F)$, applied in situ, suggested the presence of inorganic phases. X-ray diffraction analysis was used to identify crystalline phases. Fourier transform - infrared and Raman spectroscopies were used to identify the major components. Finally, gas chromatography coupled with mass spectrometry was used to identify, in the most accurate way possible, the organic compounds present in the mixtures. The combined approach of non-invasive measurements, applied for the first time to such precious objects, and of micro-invasive techniques allowed a complete characterization of the samples, widening the present view on such poorly studied materials.
\end{abstract}

KEYWORDS: ADHESIVES, JEWELLERY, BEESWAX, FT-IR, GC-MS, XRD

CHARACTERIZATION, ITALY

\section{INTRODUCTION}

The contribution of analytical chemistry to cultural heritage is particularly important in situations in which complex materials have been used to produce works of art. This is typically true in the field of jewellery. Usually, jewellery works of art were made for decorative (jewels, buckles, brooches, sword hilts etc.), magical and protective (amulets) or devotional (crucifixes, crowns and manuscript bindings) purposes. Objects in gold or silver were always attributed a magical, holy or high representative meaning, due to the significant incorruptibility of noble metals together with the demonstration of richness and the power of various commitments. It is therefore surprising that we have relatively little information on the goldsmith workshops producing these

\footnotetext{
*Received 6 June 2016; accepted 25 November 2016

†Corresponding author: email maurizio.aceto@uniupo.it

(C) 2017 University of Oxford
} 
precious objects, even if it is known that religious items were very often produced in monasteries. Concerning techniques of production, information has been obtained both from analysis of works of art and from medieval technical treatises, the most important of which is without doubt the $D e$ diversis artibus of Theophylus Presbyter (1961), a German monk who lived in the 12th century. His work is a sort of encyclopaedia of artistic technical knowledge in the Middle Ages for the field of art and craftsmanship.

The working of metals was ideally simple, as it was a matter of heating metal foils and then hammering them in order to attain the desired shape and width, or engraving them with a chisel to obtain embossed figures. The working of such thin foils, however, had to be performed on a material that was resistant enough to bear hammering, but in the same time malleable enough to allow engraving of figures on the metal. Moreover, such a material needed to have adhesive properties, because the noble metal foils might be attached to wood or any other support that functioned as a basis for the work of art. In his treatise, at book III, chapter LIX, entitled De confectione quae dicitur tenax ('Of the composition that is called tenax'), Theophylus speaks about a preparation called confectio tenax: 'Grind a piece of brick or tile very small, and melt some pitch in an earthenware pot and add a little wax. These being melted together, mingle the powder of the tile, and stir it strongly and pour it into water. And when it has begun to grow cold, dip both hands into the water and macerate it for a long time, until you can extend and draw out this composition like a skin.' Afterwards, working of the real object is described, in this case a vial: 'You instantly melt this composition and will fill the vial to the top. And when it has become cold, portray in the body and in the neck whatever you wish, and taking slender ductile instruments and a small hammer, design that which you have portrayed around it, by striking lightly. Then [...] depress the grounds that they may become hollow, and the work be raised. And when you have beaten it once throughout, the vial being brought to the fire, eject the composition, and the vial being reheated and taken from the fire again, fill it and beat as before, and do thus until you depress all the grounds equally.' In chapter LXXIV, entitled De opere ductili ('Of beaten work'), there is a clear reference to adhesive properties of such a material: '.. take wax and melt it in an earthenware or copper vessel, and mix tile, finely ground, with it, or sand, so that there may be two parts of this and a third of wax. When this has been likewise melted, you will strongly stir it with a wooden spoon, and fill up all the figures with it in gold, silver, or copper, or whatever may have been relieved in these, and cold, you will attach it where you wish.' The material cited by Theophylus therefore has a double role: it should act as an adhesive and as a filling. It has also a double composite chemical nature: the inorganic part forms the inert mass on which to work metals and can be made of sand, clay, powdered bricks and tiles, or the socalled cocciopesto (powdered bricks mixed with mortar), while the organic part works as an adhesive between metal and wood and is made of wax and/or pitch.

Concerning this material, so humble in nature and yet so fundamental in jewellery, there is scarce information in the scientific literature. To gather information useful for a comparison with our results, we found that among the few studies that can be cited, Cucchiara et al. (1998) analysed the filler material contained in the famous Corona Ferrea (5th to 9th centuries AD), held in the Museo e Tesoro del Duomo at Monza (Italy); the authors found beeswax mixed with a sort of melting ground rich in clay and quartz. Riganti et al. (2004) analysed the filler materials used in the Crocifisso del San Michele (12th century AD) at Pavia; the authors identified two different compositions, a first one, possibly the original material, made of beeswax and a second one, presumed to be later, made of a vegetal resin mixed with brick dust, powdered bone and flour. Herm (2006) analysed the filler materials contained in the Châsse des Enfants de Saint Sigismond 
(12th-13th centuries AD), held in the Abbaye de Saint-Maurice (Switzerland), using graphiteassisted laser desorption/ionization mass spectrometry; the author identified beeswax as the main material, with diterpenoid resins as additives, although no information was given on the mixed inorganic fraction present. Finally, Giostra et al. (2008) studied the binder material found in an Ostrogoth buckle (5th to 6th centuries $\mathrm{AD}$ ) with cloisonné decoration from Tortona (Alessandria, Italy) using various techniques; the inorganic part of the binder turned out to be composed of quartz, with minor amounts of feldspar, muscovite, calcite and iron oxides, while the organic part was composed of beeswax and egg white.

However, in the search for analytical information on medieval adhesive materials, some other works can be useful, in which similar materials were characterized, even if they differ with regard to typology of use and period of production. Among these studies, we must cite the works by Colombini et al. on the characterization of late Roman opus sectile (Ribechini et al. 2009), of waterproofing materials for Etruscan and Roman ships (Colombini et al. 2003) and of organic residues found inside Roman vessels and unguentaria (Colombini et al. 2003; Ribechini et al. 2008) and studies by other authors on the characterization of ancient Korean waxed paper (LattuatiDerieux et al. 2009) and of adhesives used in a Chinese sword (Luo et al. 2012). These works suggest the presence of various complex materials, ranging from beeswax to resins from plants of the Pinaceae family and oils from plants of the Brassicaceae family.

Further information, which is useful for comparison, can be found in the literature dedicated to gilding techniques, which were used in the past for the application of gold and silver leaves and foils on to various supports (Bonaduce et al. 2006; Van Der Werf et al. 2013; Andreotti et al. 2014; Antonelli et al. 2016; Biocca et al. 2016; Holclajtner-Antunović et al. 2016): in several cases, these techniques involved the use of organic adhesives. This matter has been extensively treated by Colombini et al. (2010).

In this work, adhesive materials from some early medieval jewellery works of art have been characterized, in order to compare the effective nature of these materials with information contained in medieval technical treatises. All of the works of art were produced in northern Italy between the 8 th and the 11th centuries. The analysed objects, shown in Figure 1, are as follows:

- The Ottonian Crocifisso di Vercelli, held in the cathedral of Vercelli (Italy), datable to the beginning of the 11th century (sample CroVC1). The crucifix was made in silver foil laid on a wooden core. According to tradition, some parts of the adhesive material placed between the wood and silver were replaced in a later period (sample CroVC2). The Crocifisso di Vercelli is reputed to belong to the same Lombardian school that later produced the Crocifisso del San Michele at Pavia.

- The binding of an ancient manuscript known as the Codex Eusebianus, held in the Museo del Tesoro del Duomo at Vercelli (Italy); the manuscript is datable to the 4th century AD, while the binding is datable to the mid-10th century. The binding is made of two silver covers laid on wooden boards, with embossed figures; an adhesive was used only in the rear cover (sample CodA), while in the front cover wood chippings were used under the embossed figures.

- The binding of an ancient manuscript known as the Liber Evangeliorum, held in the Museo del Tesoro del Duomo at Vercelli (Italy); the manuscript is datable to the 12th century, while in this case the binding is earlier, and datable to the mid-11th century. The binding is made of two covers laid on wooden boards, the front one in silver foil and the rear, most valuable, one in gold foil decorated with gemstones and cloisonné enamels (Senkschmelz, or the 'sunk enamel' technique). The front cover contains embossed figures with an adhesive below 

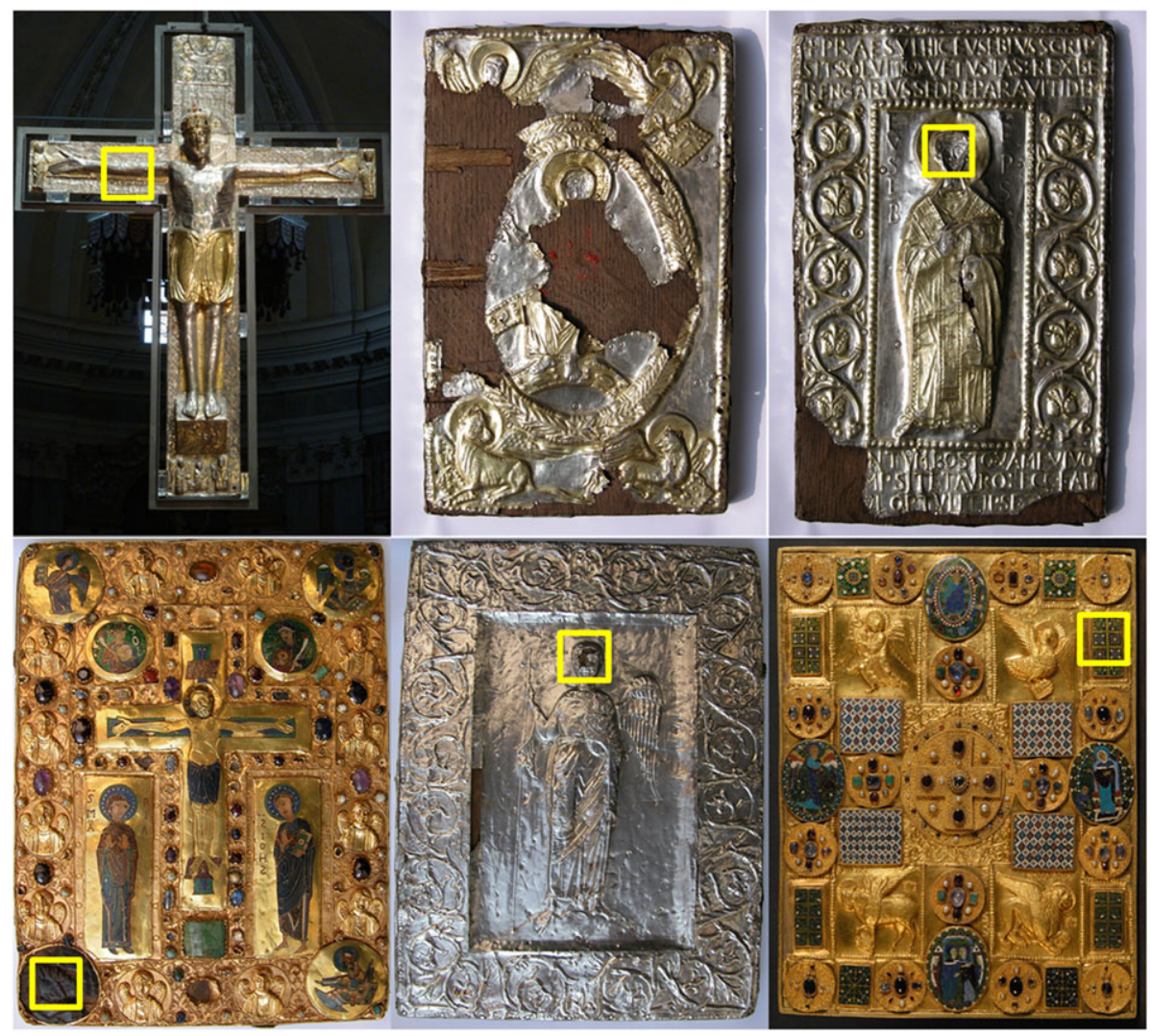

Figure 1 The works of art analysed in this study: the Crocifisso di Vercelli (top left); the front cover of the binding of the Codex Eusebianus (top centre); the rear cover of the binding of the Codex Eusebianus (top right); the front cover of the binding of the Liber Evangeliorum (bottom left); the rear cover of the binding of the Liber Evangeliorum (bottom centre); and the binding known as the Pace di Chiavenna (bottom right). The small squares indicate the points from which samples of adhesives were taken. [Colour figure can be viewed at wileyonlinelibrary.com]

(sample CodC-Ag); in the rear cover, gold plaques are present, stuck on to the board with an adhesive (sample CodC-Au).

- The binding known as the Pace di Chiavenna, held in the Museo del Tesoro at Chiavenna (Sondrio, Italy) and datable to the 11th century; the ancient manuscript once contained within it has been lost. The binding is made of a single gold cover laid on a wooden board, decorated with gemstones and cloisonné enamels; the cover contains embossed figures and plaquettes, beneath which an adhesive is present (sample PdC).

Due to the wide variety of chemical compounds present in the adhesives, various analytical techniques were used in their characterization. X-ray fluorescence spectrometry, the only technique applied in situ, was used to determine the main elements constituting the adhesives. X-ray diffraction spectroscopy was used to identify crystalline phases. FT-IR and Raman spectroscopies were used to identify major components. Finally, gas chromatography with mass spectrometric detection was used to identify, in the most accurate way possible, the organic compounds present in the mixtures. Some samples were also subjected to radiocarbon dating. 


\section{EXPERIMENTAL}

\section{$X$-ray fluorescence spectrometry}

The XRF measurements were performed using an EDXRF Thermo (Waltham, MA, USA) NITON model XL3T-900 GOLDD spectrometer, equipped with an Ag tube (max. $50 \mathrm{kV}$, $100 \mu \mathrm{A}, 2 \mathrm{~W}$ ) and a large-area SDD detector, with an energy resolution of about $136 \mathrm{eV}$ at $5.9 \mathrm{keV}$. The analysed spot had an average diameter of $8 \mathrm{~mm}$ and was focused using a CCD camera with a working distance of $2 \mathrm{~mm}$. The total time of analysis was $120 \mathrm{~s}$. The spectra obtained have been processed using the commercial software WinAxil, derived from the academic software QXAS from IAEA.

\section{FT-IR spectrophotometry}

Fourier-transformed infrared (FT-IR) profiles were measured using a Bruker Equinox 55 spectrophotometer $\left(2 \mathrm{~cm}^{-1}\right.$ resolution, 50 scansions on average). Carbon tetrachloride $\left(\mathrm{CCl}_{4}\right.$, Carlo Erba, Milan, Italy) was selected to provide an infrared solvent for the solution measurements. Solid-state patterns were collected using dry $\mathrm{KBr}$ discs (stored in packaged form at $55^{\circ} \mathrm{C}$ ).

\section{Raman spectroscopy}

Raman analysis was performed using both a dispersive and a Fourier-transform (FT-Raman) spectrometer. The analysis with the dispersive instrument was performed using a high-resolution Jobin Yvon (Villeneuve d'Ascq, France) model LabRam HR dispersive spectrophotometer, equipped with a confocal microscope. The instrument is equipped with a $633 \mathrm{~nm}$ excitation laser, 600 and 1800 lines per millimetre dispersive gratings, a $800 \mathrm{~mm}$ path monochromator and a Peltier-cooled CCD detector. The optical arrangement on the instrument gave a spectral resolution of about $4 \mathrm{~cm}^{-1}$. The whole instrument is managed by LabSpec 5 software. For the FTRaman analysis, vibrational patterns were measured using a Bruker (Ettlingen, Germany) model RFS100 spectrophotometer, provided with a Nd:YAG laser emitting at $1064 \mathrm{~nm}$ (NIR spectroscopic region) and a liquid-nitrogen-cooled Ge detector $\left(4 \mathrm{~cm}^{-1}\right.$ resolution); measurements were made with an irradiation laser power in the range $35-75 \mathrm{~mW}$ and averaged over 1500 scans.

\section{$X$-ray diffraction analysis}

The XRD analysis was performed using a Bragg-Brentano PANalytical (Almelo, The Netherlands) X'Pert diffraction system, equipped with a copper anode and an Ultrafast ${ }^{\mathrm{TM}}$ detec- $^{\text {Th }}$ tor, working at $40 \mathrm{kV}$ and $30 \mathrm{~mA}$, with a measurement path of $0.002^{\circ} 2 \theta$ at $30 \mathrm{~s}$ per step. Samples were analysed after milling, so that in the analysis of the data, a possible effect of preferential orientation, provided by some series of crystallographic planes, has been taken into account.

\section{Gas chromatography - mass spectrometry}

The GC-MS analysis was performed following the procedure described in Ribechini et al. (2009). A volume of $2.0 \mu \mathrm{L}$ of the derivatized sample was injected into a gas chromatographic system (CP3800, Varian, Walnut Creek, CA, USA) coupled with a mass spectrometric detection system (2200 Saturn, Varian). The separation was performed on a VF-5MS $(30 \mathrm{~m} \times 0.25 \mathrm{~mm} \times 0.25 \mu \mathrm{m})$ stationary phase purchased from Varian. The carrier gas was

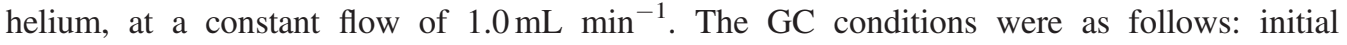


temperature $80^{\circ} \mathrm{C}$, hold for $2 \mathrm{~min}$, then up to $200^{\circ} \mathrm{C}$ at $10^{\circ} \mathrm{C} \mathrm{min}^{-1}$, and then up to $280^{\circ} \mathrm{C}$ at $6^{\circ} \mathrm{C} \mathrm{min}{ }^{-1}$, temperature hold for $17 \mathrm{~min}$. The injector port was set at a constant temperature of $280^{\circ} \mathrm{C}$. The MS detector was equipped with an electron ionization source (EI at $70 \mathrm{eV}$ ) and worked in full scan acquisition mode in the range of $m / z, 50-650$. The temperatures of the ion trap, the manifold and the transfer line were set at $230^{\circ} \mathrm{C}, 80^{\circ} \mathrm{C}$ and $250^{\circ} \mathrm{C}$, respectively. Peak assignments were performed by comparison of the acquired mass spectra with the NIST 2.0 mass spectral libraries.

\section{${ }^{14} \mathrm{C}$ dating}

The ${ }^{14} \mathrm{C}$ analyses were performed at the Centro Universitario di Datazioni of Università degli Studi di Milano-Bicocca. The conventional radiocarbon age (tRC) has been calibrated by means of the OxCal v.4 software, using the IntCal04 calibration curve (Bronk Ramsey 1995) and hence converted into calendar years.

\section{RESULTS AND DISCUSSION}

The application of various analytical techniques was justified by the complex nature of the samples, all of which were composed of a mixed multi-component inorganic/organic matrix. After performing non-invasive in situ XRF measurements, small amounts of adhesives were taken from works of art using a scalpel, in order to perform non-destructive spectroscopic measurements with the other techniques. The final stage was chromatographic separation and identification of chemical markers performed by GC-MS analysis, this being a destructive method.

\section{$X$-ray fluorescence spectrometry}

The XRF technique analysis can only be relevant with regard to elements that suggest the presence of inorganic materials. The results are summarized in Table 1 (a). In the case of sample PdC, only light elements were detected, which suggests a totally organic composition. In samples CroVC1, CodA, CodC-Ag and CodC-Au, the presence of Si highlighted the use of siliceous materials; other elements identified were $\mathrm{Ca}, \mathrm{Fe}$ and $\mathrm{S}$, which can indicate that both gypsum and iron oxides were present. In sample CroVC2, which was considered to come from a later addition, the $\mathrm{XRF}$ analysis revealed the contextual presence of $\mathrm{Ba}$ and $\mathrm{S}$, which strongly suggests the use of baryte $\left(\mathrm{BaSO}_{4}\right)$, possibly introduced as a filler. The first citations of baryte are datable to 1556 in the De re metallica by Agricola (Georgius Agricola 1950), in which this material is mentioned as spat; subsequently, a rock called the 'Bologna stone', made of barium sulphate, was cited in texts starting from the beginning of the 17th century. Examples of spectra from the XRF analysis of the adhesives are reported in Figure 2 (a), where a comparison is shown between sample CroVC1 and sample CroVC2.

\section{FT-IR spectrophotometry}

Analysis by means of FT-IR spectrophotometry allowed us to acquire an overall image of the phases present in the samples; this technique has already proved to be useful in the preliminary characterization of similar materials (Colombini et al. 2003; Font et al. 2007). Two groups of materials were identified:

- A first group characterized by the massive presence of beeswax, together with inorganic phases; this group comprises samples CroVC1, CodA, CodC-Ag and PdC. 
Table 1 Lists of (a) elements identified by means of XRF analysis, (b) phases identified by means of XRD analysis, and (c) chemical markers identified by means of GC-MS analysis; (d) the final composition of the analysed samples; (e) the results of ${ }^{14} \mathrm{C}$ dating

\begin{tabular}{|c|c|c|c|c|c|c|}
\hline & CroVC1 & CroVC2 & CodA & CodC-Ag & CodC-Au & $P d C$ \\
\hline \multicolumn{7}{|l|}{ (a) Elements } \\
\hline $\mathrm{Ba}$ & - & $x$ & - & - & - & - \\
\hline $\mathrm{Ca}$ & $x$ & - & $x^{*}$ & - & $x$ & $x^{*}$ \\
\hline $\mathrm{Sr}$ & $x^{*}$ & $x^{*}$ & - & - & $x$ & - \\
\hline $\mathrm{Cl}$ & $x$ & $x^{*}$ & - & - & $x^{*}$ & - \\
\hline $\mathrm{Fe}$ & $x$ & - & $x^{*}$ & $x^{*}$ & - & - \\
\hline $\mathrm{K}$ & - & - & $x$ & $x$ & $x$ & - \\
\hline $\mathrm{S}$ & $x$ & $x$ & - & - & $x$ & - \\
\hline $\mathrm{Si}$ & $x$ & - & $x$ & $x$ & $x$ & $x^{*}$ \\
\hline \multicolumn{7}{|l|}{ (b) Phases } \\
\hline Anhydrite & $x$ & - & - & - & $x$ & - \\
\hline Baryte & - & $x$ & - & - & - & - \\
\hline Bassanite & - & - & - & - & $x$ & - \\
\hline Gypsum & $x$ & - & - & - & $x$ & - \\
\hline Paraffin & $x$ & - & - & - & - & - \\
\hline Quartz & $x$ & - & $x$ & $x$ & $x$ & - \\
\hline Clay mineral & - & - & $x$ & $x$ & $x$ & - \\
\hline \multicolumn{7}{|l|}{ (c) GC-MS markers } \\
\hline Palmitic acid** & $x$ & - & $x$ & $x$ & - & $x$ \\
\hline Octadecanoic acid $* *$ & $x$ & - & $x$ & $x$ & - & $x$ \\
\hline $\begin{array}{l}\text { Hydroxyhexadecanoic } \\
\text { acid** }\end{array}$ & $\times$ & - & $x$ & $\times$ & - & $x$ \\
\hline 1-Tetracosanol ${ }^{* *}$ & $x$ & - & $x$ & $x$ & - & $x$ \\
\hline Lignoceric acid $* *$ & $\times$ & - & $x$ & $x$ & - & $\times$ \\
\hline 1-Triacontanol** & $x$ & - & $x$ & $x$ & - & $x$ \\
\hline Dehydroabietic acid** & . & $x$ & . & . & $x$ & . \\
\hline $\begin{array}{l}\text { 7-Oxodehydroabietic } \\
\text { acid*** }\end{array}$ & . & $x$ & . & . & $x$ & . \\
\hline $\begin{array}{l}15 \text {-Hydroxy-7- } \\
\text { oxodehydroabietic } \\
\text { acid** }\end{array}$ & . & $x$ & . & . & $x$ & . \\
\hline Retene & - & $x$ & - & - & $x$ & - \\
\hline \multicolumn{7}{|l|}{ (d) Objects } \\
\hline Organic part & Beeswax & Pine pitch & Beeswax & Beeswax & Pine pitch & Beeswax \\
\hline Inorganic part & $\begin{array}{l}\text { Calcium } \\
\text { sulphates/sand }\end{array}$ & Baryte & $\begin{array}{l}\text { Sand/ } \\
\text { clay }\end{array}$ & Sand/clay & $\begin{array}{l}\text { Calcium } \\
\text { sulphates/ } \\
\text { sand/clay }\end{array}$ & - \\
\hline \multicolumn{7}{|l|}{ (e) ${ }^{14} \mathrm{C}$ dating } \\
\hline tRC (years BP) & $\mathrm{AD} 1018 \pm 117$ & $\mathrm{AD} 444 \pm 57$ & $* * *$ & $\mathrm{AD} 1271 \pm 64$ & AD $949 \pm 81$ & $\mathrm{AD} 1042 \pm 36^{\dagger}$ \\
\hline Calibrated date $( \pm 1 \sigma)$ & AD 895-1155 & AD 1410-1615 & $* * *$ & AD $665-810$ & $\begin{array}{c}\text { AD 1015- } \\
1175\end{array}$ & AD 975-1025 \\
\hline Calibrated date $( \pm 2 \sigma)$ & AD 770-1255 & AD $1330-1635$ & $* * *$ & AD $650-890$ & AD $900-1260$ & AD $895-1040^{\dagger}$ \\
\hline
\end{tabular}

*Element present at level $<1 \%$.

**Identified as trimethylsilyl ester.

***Analysis not executed.

${ }^{\dagger}$ Data extracted from Maspero et al. (2012). 
(a)
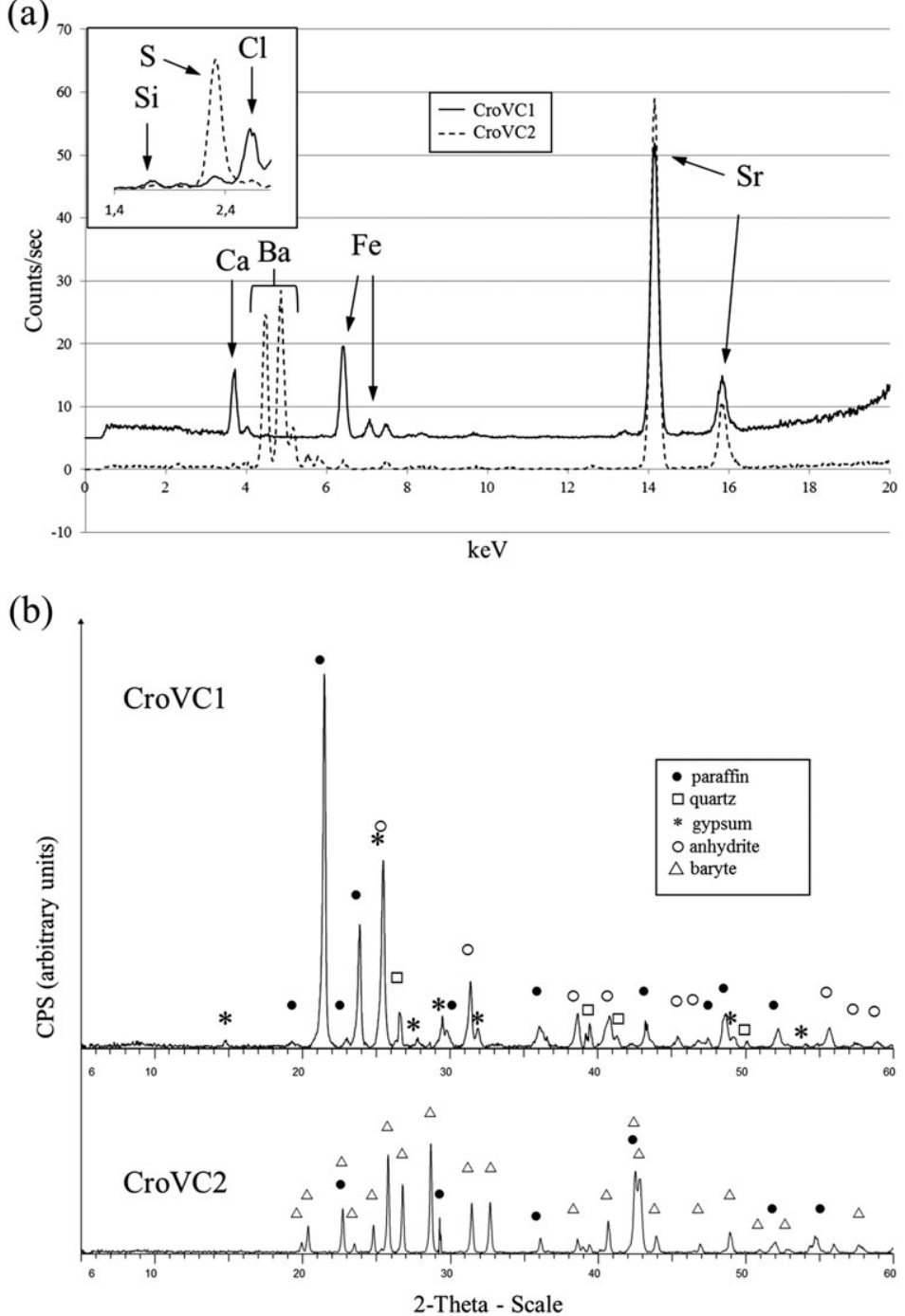

Figure 2 Results from the X-ray analysis of samples CroVC1 and CroVC2: (a) XRF spectrometry; (b) XRD patterns.

- A second group characterized by a resinous material with inorganic phases; this group comprises samples CroVC2 and CodC-Au.

The FT-IR spectra of the main organic phases characterizing the two groups are shown in Figure 3. The spectrum of sample PdC (Fig. 3 (b)), representative of the group containing beeswax, fits very well with the spectrum that is diagnostic of modern beeswax (Fig. 3 (a)). It is characterized by bands at 2955, 2917 and $2849 \mathrm{~cm}^{-1}$, a minor absorption at $2645 \mathrm{~cm}^{-1}$, resulting from a second-order overtone or combination mode vibrations, and then bands at 1737, 1712 (not well resolved), 1473, 1463, 1377, 1175, 957 and $719 \mathrm{~cm}^{-1}$, due to vibration modes typical of long-chain aliphatic molecules such as those present in paraffins (Socrates 2001). Peaks at 2955, 2917 and $2849 \mathrm{~cm}^{-1}$ are typical of the asymmetric and symmetric stretching modes of $\mathrm{CH}_{3}-, \mathrm{CH}_{2}-$ and $\mathrm{CH}-$ aliphatic groups, whereas the strong peaks at 1473,1463 and 


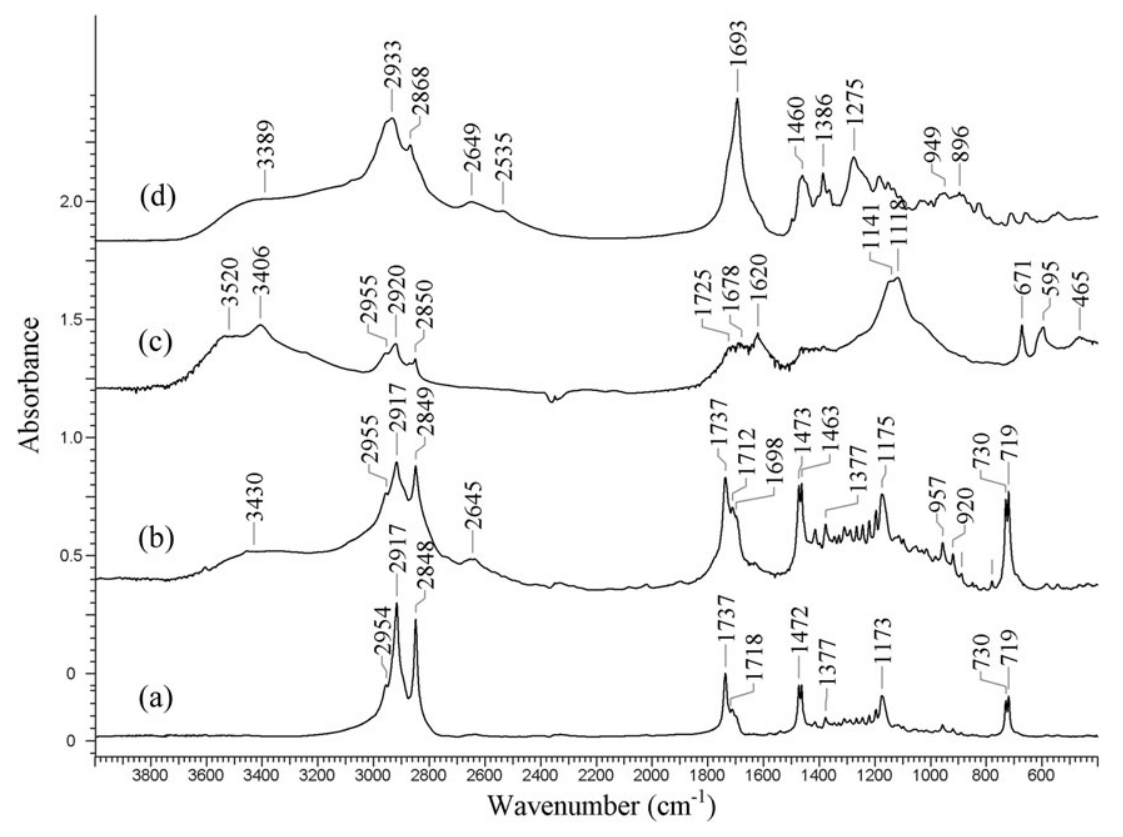

Figure 3 FT-IR spectra from: (a) a standard beeswax; (b) sample PdC; (c) sample CodC-Au; (d) a standard colophony.

$1377 \mathrm{~cm}^{-1}$ are basically due to the asymmetric and symmetric bending modes of methylene moieties. The spectral range between 1480 and $1200 \mathrm{~cm}^{-1}$ is overfilled by an overlap set of multiple low peaks. They result from the comprehensive mixed coupling $\mathrm{C}-\mathrm{C}$ stretching and $\mathrm{C}-\mathrm{H}$ bending modes of hydrocarbon groups. The strong peaks at 730 and at $719 \mathrm{~cm}^{-1} \mathrm{can}$ be ascribed to the out-of-plane rocking skeletal modes of these moieties. These are specific to long-chain aliphatic substituents, such as the esters in beeswax. The doublet occurring at 1737 and $1712 \mathrm{~cm}^{-1}$ is due to the vibration modes typical of carbonyl moieties in ester and carboxylic acid arrangements. Esters are responsible for the peak occurring at $1175 \mathrm{~cm}^{-1}$, due to $\mathrm{C}-\mathrm{O}$ stretching modes, while the peak at $957 \mathrm{~cm}^{-1}$ can be due to out-of-plane bending of the $\mathrm{OH}$ - function in carboxylic acids. To summarize, a matching overlap can be observed between a standard reference for modern beeswax and beeswax group materials in the samples (CroVC1, CodA, CodC-Ag and PdC). Indeed, these results can be related to a good conservation state of beeswax in the works of art, according to the lack of signals typical of wax degradation, such as a lowering of the bands of esters or the occurrence of bands due to alcohols (Regert et al. 2001).

In samples CodC-Au (Fig. 3 (c)) and CroVC2, broad O-H absorptions in the $3500-3400 \mathrm{~cm}^{-1}$ spectral range, the broad overlap of peaks in the $3000-2800 \mathrm{~cm}^{-1} \mathrm{C}-\mathrm{H}$ aliphatic stretching range, the featured strong absorptions set at $1700 \mathrm{~cm}^{-1}$ and lower wavenumbers, minor multiple peaks in the $1500-1300 \mathrm{~cm}^{-1}$ range, and very strong absorptions at about $1100 \mathrm{~cm}^{-1}$ and in the $700-500 \mathrm{~cm}^{-1}$ skeletal region can be tentatively related to a complex non-stoichiometric material derived from colophony (Fig. 3 (d), standard colophony). It is noteworthy that the higher relative intensities of the alcoholic, carboxylic and ether group regions and the lack of the characteristic pattern of the overtone region of carboxylic acids in the range $2500-2700 \mathrm{~cm}^{-1}$ support a comprehensive major degradation of these natural applied supporting products, such as that 
occurring when colophony is intentionally subjected to boiling, to obtain pitch. In the ether region, the strong absorptions may also result from supplementary inorganic fillers (i.e., sulphates) (Socrates 2001).

FT-IR solution measurements performed in $\mathrm{CCl}_{4}$ were provided to distinguish the inorganic and soluble organic adhesive components. Indeed, in all samples other than $\mathrm{PdC}$, solid inorganic materials, mixed with both the main beeswax and colophony adhesives, could be left after organic solvent extraction, which provided features specific to infrared solution patterns. They supported the occurrence of inorganic phases, which have been characterized by the results of the XRF, XRD and Raman analyses.

\section{Raman spectroscopy}

Raman analysis allowed us to focus our attention on microscopic sections of the samples, therefore identifying selective phases. This analysis substantially confirmed the presence of beeswax in samples CroVC1, CodA, CodC-Ag and PdC. In all instances, a neat spectrum was obtained using the Raman dispersive system, which is another clue for assessing the good conservation state of this component. As for samples CroVC2 and CodC-Au, Raman analysis with an FT spectrometer did not add any further clues to the possible identification of colophony. As for inorganic components, Raman analysis performed using the dispersive system allowed us to support the identification of some mineral phases - that is, baryte, gypsum and quartz-due to its large spatial resolution.

\section{$X$-ray diffraction analysis}

The high diagnostic power of the X-ray diffraction technique allowed us to enlarge the set of compounds identified in the analysed samples, particularly with regard to inorganic constituents. All samples containing beeswax showed the pattern typical of paraffins, with peaks occurring at 21.5 and $23.82 \theta$; sample PdC did not show any other component, which suggested that it was made of pure beeswax. Interestingly, evidence was found of mineral phases that were different from clay minerals, which seems to suggest that other materials were used in addition, or as an alternative, to clay, brick dust or cocciopesto. Sample CroVC2 was of particular interest in that it showed only the presence of baryte, as already suggested by the previous analyses. Table 1 (b) reports the list of molecules identified by means of XRD analysis, while examples of XRD patterns from adhesives are reported in Figure 2 (b), where a comparison is again shown between sample CroVC1 and sample CroVC2.

\section{Gas chromatography - mass spectrometry analyses}

GC-MS analysis was performed on a very limited amount of sample, between 2 and $3 \mathrm{mg}$ of material. As described in Ribechini et al. (2009) and extensively in Colombini and Modugno (2009), this analysis is aimed at identifying those compounds that constitute the chemical markers of the starting materials. The following molecules are particularly representative:

- abietic acid and its derivatives - these diterpenoid acids are markers of colophony and pine pitch;

- retene-this polycyclic aromatic hydrocarbon is a marker for the high-temperature conversion of colophony into pitch (Marchand-Geneste and Carpy 2003);

- palmitic acid-along with other long-chain carboxylic acids, their esters and long-chain alcohols, this is a typical marker of beeswax (Colombini et al. 2003 and references therein); and 
- betulin-along with lupeol and lupenone, this is a marker of birch bark tar (Regert and Rolando 2002).

Table 1 (c) reports the list of the most relevant molecules identified by means of GC-MS analysis. In the case of samples CroVC1, CodA, CodC-Ag and $\mathrm{PdC}$, the identification of palmitic acid, along with octadecanoic acid $\left(\mathrm{C}_{18}\right.$ acid), hydroxyhexadecanoic acid $\left(\mathrm{OH}-\mathrm{C}_{16}\right.$ acid), 1-tetracosanol $\left(\mathrm{C}_{24}\right.$ alcohol), lignoceric acid $\left(\mathrm{C}_{24}\right.$ acid) and 1-triacontanol $\left(\mathrm{C}_{30}\right.$ alcohol$)$, can be seen as confirmation of the results obtained by the previous spectroscopic measurements; in other words, that beeswax is the main organic material used as an adhesive. All the molecules cited were identified mostly in the acidic fraction obtained using the procedure described by Ribechini et al. (2009). As for samples CroVC2 and CodC-Au, for which materials other than beeswax were suggested by spectroscopic analyses, GC-MS analysis allowed us to identify abietic acid derivatives (dehydroabietic acid and oxidation products such as 7-oxodehydroabietic acid and 15-hydroxy-7-oxodehydroabietic acid) but also retene, a polycyclic aromatic hydrocarbon that is known to be the main product formed when colophony is boiled at high temperatures to transform it into pitch. Retene, therefore, is a clear clue to the presence of an adhesive obtained from pine pitch rather than from colophony. In this case also, the molecules cited were identified mostly in the acidic fraction, apart from retene, which was better identified in the neutral fraction.

Finally, Table 1 (d) summarizes the main components of the adhesives analysed, according to the results of all measurements.

\section{${ }^{14} \mathrm{C}$ dating}

Additionally to the chemical characterization of the samples, some of them were subjected to ${ }^{14} \mathrm{C}$ dating in order to confirm the information obtained. The points of particular interest were as follows:

- a comparison of samples CroVC1 and CroVC2 - these materials, which turn out to be completely different from the point of view of composition, are also considered to be different with regard to time, with $\mathrm{CroVC} 2$ reputed to be later; and

- a comparison of samples CodC-Ag and CodC-Au-although belonging to an object considered as homogeneous (they come from the two covers of the binding of the Liber Evangeliorum), these materials are sufficiently different to be considered as applied by different artists or at different times.

Table 1 (e) reports data for the analysed samples. The material of the binding of the Codex Eusebianus (sample code CodA) was not analysed, since this work of art is the only one that can be dated with relative accuracy: on the rear cover, it bears the name Berengarius, which can be related to Berengarius I, King of Italy between AD 888 and 924, or Berengarius II, King of Italy between AD 950 and 961 .

It must be pointed out that ${ }^{14} \mathrm{C}$ analysis cannot date the moment of effective use of adhesives but, rather, the moment at which the raw materials were naturally produced. In the case of beeswax, this can be safely referred to the secretion of wax by bees; while in the case of pitch and tar, this can tentatively refer to the secretion by trees. In both cases, considering the high hydrophobicity of these materials (and therefore their chemical resistance to the effect of water), the period of use could be far from the moment of production, even in terms of years.

Dating of samples from the Crocifisso di Vercelli (CroVC1 and CroVC2) confirms that the former is the original adhesive material used by the Ottonian artists, while the latter is an addition made in Renaissance or Baroque times, in optimal agreement with the identification therein of baryte. 

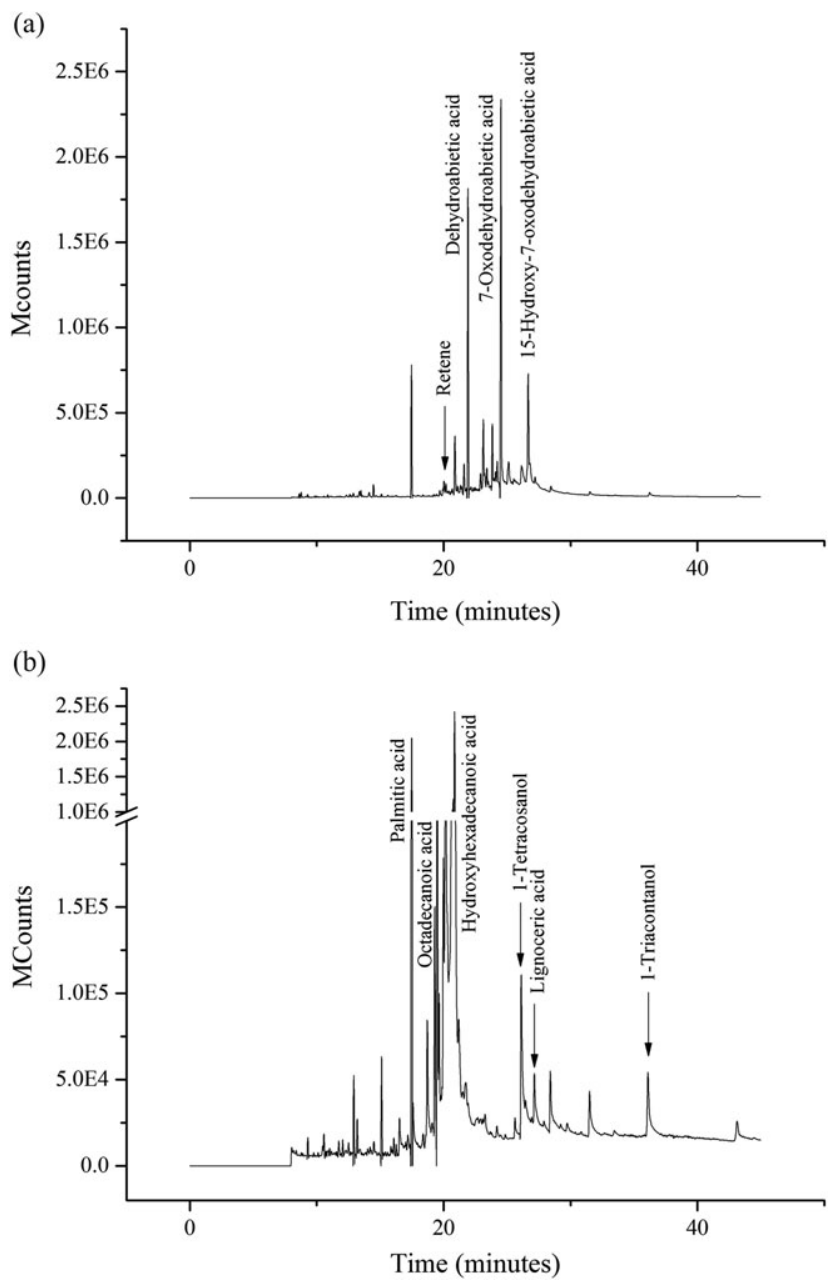

Figure 4 Examples of GC-MS chromatograms: (a) sample CodC-Au (acid fraction); (b) sample CodC-Ag (acid fraction).

As for the samples from the binding of the Liber Evangeliorum (CodC-Ag and CodC-Au; GCMS chromatograms are shown in Fig. 4), these materials appear to be chemically different and this information overlaps with their dating, the adhesive from the Ag cover being much older than the one from the Au cover. These data could seemingly support the hypothesis that the two covers were made by different artists at different times, and then joined in the 11th century when the binding was constructed in order to host the Liber Evangeliorum manuscript. On the other side, due to formal, technical and stylistic elements (Lomartire 2015), it seems more likely that the different materials have to be explained in relation to their very different functions: as a moderately soft support for the finishing of the repoussé work in the silver cover, and merely as a thick layer of adhesive in the gold one. Moreover, the older dating of the wax in the silver cover should be considered from the viewpoint of medieval workshop practices, which involved the use, or reuse, of new raw materials as well as old ones. 


\section{CONCLUSIONS}

The combined application of various spectroscopic and chromatographic techniques has allowed us to obtain a thorough comprehensive characterization of the materials used as adhesives in highly precious medieval jewellery works of art. The use of non-invasive techniques applied in situ for the first time on such precious objects is particularly relevant. The identification of beeswax is coherent with previous studies on this subject. The use of beeswax as a binding agent can, in fact, be dated back at least at the Neolithic age in the Western world (Regert et al. 2001; Luo et al. 2012), while relatively less knowledge has been acquired on the use of resins for the same task. The information obtained from the chemical analysis fitted well with the dating yielded by means of ${ }^{14} \mathrm{C}$ analysis.

\section{ACKNOWLEDGMENTS}

We would like to thank the Fondazione Museo del Tesoro del Duomo e Archivio Capitolare at Vercelli, in the persons of its president, Enzo Pozzolo, Dr Anna Cerutti Garlanda (responsible for the modern collection) and Dr Timoty Leonardi (responsible for the medieval collection) for allowing us to take samples of adhesives from Crocifisso di Vercelli and the bindings of the Codex Eusebianus and the Liber Evangeliorum for the same reason we want to acknowledge the contribution of the Soprintendenza ai Beni Artistici e Storici del Piemonte and the Capitolo Metropolitano della Cattedrale di S. Eusebio; finally, we would like to thank Professor Chiara Maggioni (Università Cattolica del Sacro Cuore, Milan) for providing a sample of adhesive from the Pace di Chiavenna.

\section{REFERENCES}

Andreotti, A., Bonaduce, I., Castelvetro, V., Colombini, M. P., Lluveras-Tenorio, A., Raihane, M., Ibnoussina, M., and Boujamid, A., 2014, Characterization of the organic materials used in the painting of the vaulted ceiling at the Saadian Tomb of Mulay Ahmed Al-Mansour (Marrakech), Journal of Cultural Heritage, 15, 300-7.

Antonelli, F., Lazzarini, L., Cancelliere, S., and Tesser, E., 2016, Study of the deterioration products, gilding, and polychromy of the stones of the Scuola Grande di San Marco's façade in Venice, Studies in Conservation, 61, 74-85.

Biocca, P., Santopadre, P., Sidoti, G., Sotgiu, G., de Notaristefani, F., and Tortora, L., 2016, ToF-SIMS study of gilding technique in the fresco Vela della Castità by Giotto's school, Surface and Interface Analysis, 48, 404-8.

Bonaduce, I., Colombini, M. P., and Diring, S., 2006, Identification of garlic in old gildings by gas chromatography mass spectrometry, Journal of Chromatography A, 1107, 226-32.

Bronk Ramsey, C., 1995, Radiocarbon calibration and analysis of stratigraphy: the OxCal program, Radiocarbon, 37, 425-30.

Colombini, M. P., and Modugno, F., 2009, Organic mass spectrometry in art and archaeology, Wiley, New York.

Colombini, M. P., Andreotti, A., Bonaduce, I., Modugno, F., and Ribechini, E., 2010, Analytical strategies for characterizing organic paint media using gas chromatography/mass spectrometry, Accounts of Chemical Research, 43, 715-27.

Colombini, M. P., Giachi, G., Modugno, F., Pallecchi, P., and Ribechini, E., 2003, The characterisation of paints and waterproofing materials from the shipwrecks found at the archaeological site of the Etruscan and Roman Harbour of Pisa (Italy), Archaeometry, 45, 659-74.

Cucchiara, A., Mairani, A., and Mannoni, T., 1998, Analisi dei granuli di stucco terroso, in La corona ferrea nell'Europa degli imperi, vol. II: Alla scoperta del prezioso oggetto (ed. G. Buccellati), 52-60, Editoriale Giorgio Mondadori, Milano.

Font, J., Salvadó, N., Butí, S., and Enrich, J., 2007, Fourier transform infrared spectroscopy as a suitable tehcnique in the study of the materials used in waterproofing of archaeological amphorae, Analytica Chimica Acta, 598, 119-27.

Georgius Agricola, 1950, in De re metallica (eds. H. C. Hoover and L. H. Hoover), Dover Publications, New York.

Giostra, C., Bruni, S., Guglielmi, V., Rottoli, M., and Rettore, E., 2008, The Ostrogothic buckle with cloisonné decoration from Tortona (Italy), Archäologisches Korrespondenzblatt, 38, 577-96. 
Herm, C., 2006, La Châsse des enfants de saint Sigismond de l'Abbaye de Saint-Maurice: analysis of the filler material using graphite-assisted laser desorption/ionisation mass spectrometry, in Medieval reliquiary shrines and precious metal objects (eds. K. Anheuser and C. Werner), 17-24, Archetype, London.

Holclajtner-Antunović, I., Stojanović-Marić, M., Bajuk-Bogdanović, D., Žikić, R., and Uskoković-Marković, S., 2016, Multi-analytical study of techniques and palettes of wall paintings of the monastery of Žiča, Serbia, Spectrochimica Acta Part A, 156, 78-88.

Lattuati-Derieux, A., Egasse, C., Regert, M., Chung, Y., and Lavédrine, B., 2009, Characterization and degradation pathways of ancient Korean waxed papers, Journal of Cultural Heritage, 10, 422-7.

Lomartire, S., 2015, Tabula ornata lapidibus diversorum colorum: la legatura preziosa del Codice C nel Museo del Tesoro del Duomo di Vercelli, Viella, Roma.

Luo, W., Li, T., Wang, C., and Huang, F., 2012, Discovery of beeswax as binding agent on a 6th-century BC Chinese turquoise-inlaid bronze sword, Journal of Archaeological Science, 39, 1227-37.

Marchand-Geneste, N., and Carpy, A., 2003, Theoretical study of the thermal degradation pathways of abietane skeleton diterpenoids: aromatization to retene, Journal of Molecular Structure: THEOCHEM, 635, 55-82.

Maspero, F., Maggioni, C., and Castelletti, L., 2012, The Chiavenna Evangelistary cover: a radiocarbon dating of a supposed Ottonian goldsmiths' work, in Proceedings: 39th International Symposium on Archaeometry (ISA 2012), 28 May - 1 June 2012, Leuven, Belgium (eds. R. B. Scott, D. Braekmans, M. Carremans, and P. Degryse), 57-9, Centre for Archaeological Sciences, KU Leuven, Leuven.

Regert, M., and Rolando, C., 2002, Identification of archaeological adhesives using direct inlet electron ionization mass spectrometry, Analytical Chemistry, 74, 965-75.

Regert, M., Colinart, S., Degrand, L., and Decavallas, O., 2001, Chemical alteration and use of beeswax through time: accelerated ageing tests and analysis of archaeological samples from various environmental contexts, Archaeometry, 43, 549-69.

Ribechini, E., Modugno, F., Colombini, M. P., and Evershed, R. P., 2008, Gas chromatographic and mass spectrometric investigations of organic residues from Roman glass unguentaria, Journal of Chromatography A, 1183, 158-69.

Ribechini, E., Orsini, S., Silvano, F., and Colombini, M. P., 2009, Py-GC/MS, GC/MS and FTIR investigations on late Roman-Egyptian adhesive from opus sectile: new insights into ancient recipes and technologies, Analytica Chimica Acta, 638, 79-87.

Riganti, V., Giaccio, M., and Baldi, M., 2004, Analisi materica sul Crocifisso del San Michele: il materiale di riempimento, Quaderni di Scienza della Conservazione, IV, 267-76.

Socrates, G., 2001, Infrared and Raman characteristic group frequencies, 3rd edn, Wiley, New York.

Theophilus Presbyter, 1961, in The various arts (ed. C. R. Dodwell), Thomas Nelson, London.

Van Der Werf, I. D., Calvano, C. D., Laviano, R., Simonetti, A., and Sabbatini, L., 2013, Multi-technique chemical characterisation of a 12-13th-century painted crucifix, Microchemical Journal, 106, 87-94. 